\title{
Extrahepatic intraductal biliary cystadenomas: Solving the mystery of "Idiopathic biliary obstruction"? A tertiary care institute experience
}

\author{
Sugi R. V. Subramaniam, Sugumar Chidambaranathan, \\ Senthil Kumar, Prabhakaran Raju, Jeswanth Sathyanesan, \\ Ravichandran Palaniappan
}

\begin{abstract}
Introduction: Biliary cystadenoma is a rare benign neoplasm of the liver with less than 200 cases being reported all over the world. The greatest challenge in the management of biliary cystadenoma lies in the pre-operative diagnosis, since it is most often misdiagnosed as simple liver cyst or hydatid cyst. We report a series of 12 cases highlighting the radiological findings and problems related to its management with special focus on intrahepatic biliary cystadenomas; a very unusual benign cause of obstructive jaundice and their management. Case Series: Records of
\end{abstract}

Sugi R. V. Subramaniam ${ }^{1}$, Sugumar Chidambaranathan ${ }^{2}$, Senthil Kumar ${ }^{3}$, Prabhakaran Raju${ }^{4}$, Jeswanth Sathyanesan $^{5}$, Ravichandran Palaniappan ${ }^{6}$

Affiliations: ${ }^{1}$ Post Graduate Resident, Institute of Surgical Gastroenterology \& Liver Transplant Govt. Stanley Medical College, Chennai, Tamil Nadu, India; ${ }^{2}$ Professor, Institute of Surgical Gastroenterology \& Liver Transplant, Govt. Stanley Medical College, Chennai, Tamil Nadu, India; ${ }^{3}$ Assistant Professor, Institute of Surgical Gastroenterology \& Liver Transplant, Govt. Stanley Medical College, Chennai, Tamil Nadu, India; ${ }^{4}$ Assistant Professor, Institute of Surgical Gastroenterology \& Liver Transplant, Chennai, Tamil Nadu, India; ${ }^{5}$ Professor, Institute of Surgical Gastroenterology \& Liver Transplant, Govt. Stanley Medical College, Chennai, Tamil Nadu, India; ${ }^{6}$ Professor\& Head of Department, Institute of Surgical Gastroenterology \& Liver Transplant, Govt. Stanley Medical College, Chennai, Tamil Nadu, India.

Corresponding Author: Dr. Sugi R. V. Subramaniam, 601, Old Jail Road, Institute of Surgical Gastroenterology \& Liver Transplant, Govt. Stanley Medical College, Chennai, Royapuram, Tamil Nadu 600001, India; Email:drrvsugi@ gmail.com

Received: 23 May 2018

Accepted: 22 June 2018

Published: 19 July 2018
12 patients who underwent surgery for biliary cystadenomas, between 2013 and 2016, were reviewed and analysed retrospectively. Of the 12 patients with biliary cystadenomas, three patients had features of obstructive jaundice in the absence of any other recognized cause of biliary obstruction. Majority of the patients were females. The most frequent symptom was abdominal pain (92\%); with obstructive jaundice seen in three patients (25\%). All patients were subjected to routine blood investigations with Liver function tests and in addition Serum CA 19-9 was done. We had three patients who had protruding mass like lesion into the biliary tract causing obstruction to bile flow. MRI with MRCP was done in all patients before subjecting them to surgical exploration; who were managed with extrication of the growth along with enucleation/ resection. There has been no recurrence during the follow-up period ranging from six months to three years. All 12 patients underwent surgical management which included enucleation in four patients and non-anatomical liver resection in eight patients and some in addition required T-tube drainage of the bile duct. Totally 25 cases of Biliary Cystadenomas have been managed in our Institute till date with only three cases of Obstructive jaundice. Conclusion: In patients with obstructive jaundice, especially middle aged women, with the background of normal CA 19-9 levels and a polypodal mass projecting into the bile duct lumen intraductal biliary cystadenomas should be considered as a possible diagnosis. If feasible limited resection of the cyst with extrication of this benign lesion with close follow up and frequent imaging of the liver is advisable to locate early recurrences if any.

Keywords: Biliary cystadenoma, Episodic jaundice, Obstructive jaundice 


\section{EDORIUM Journals}

\section{How to cite this article}

Sugi R V, Sugumar C, Senthil Kumar P, Prabhakaran R, Jeswanth S, Ravichandran P. Extrahepatic intraductal biliary cystadenomas: Solving the mystery of "Idiopathic biliary obstruction"? A tertiary care institute experience. Int J Hepatobiliary Pancreat Dis 2018;8:100078Z04SS2018.

Article ID: 100078Zo4SS2018

$* * * * * * * * *$

doi: 10.5348/100078Zo4SS2018CS

\section{INTRODUCTION}

The most common causes for obstructive jaundice include biliary calculi, strictures (benign \& malignant) and various intrahepatic or extrahepatic malignancies. However, it is important to be aware of rare yet surgically correctable causes of obstructive jaundice, one of them being biliary cystadenomas (BCA). They are benign cystic lesions of biliary origin, accounting for less than $5 \%$ of nonparasitic cysts of the liver, and mostly occurring in middle-aged women (90\%) [1]. Though benign, they carry a certain malignant potential, [2] and preoperative differentiation between the two may often be impossible. BCA arise from either an aberrant bile duct or from primitive hepatobiliary stem cells, with majority of them being intrahepatic (85\%) [3, 4]. They are commonly misdiagnosed and managed as a simple cyst or a hydatid cyst, resulting in a very high rate of recurrence (>90\%) [5]. Fewer than 100 cases of intrahepatic biliary cystadenomas have been reported in medical literature till date, of which less than 10\% have presented with obstructive jaundice [6]. Sastha et al from our Institute reported one of the largest case series of 13 cases of biliary cystadenomas and their management [7]. We have managed 12 cases of BC over the past four years, with three cases presenting with obstructive jaundice. This takes the tally of BCAs managed in our Institute to 25 cases over the past 10 years. We present our series of BCA presenting with obstructive jaundice thereby highlighting the potential pitfalls in the diagnosis and the diagnostic conundrum which these lesions may present.

\section{CASE SERIES}

Records of patients with histologically confirmed biliary cystadenomas admitted between July 2013 and June 2016 at our Institute were reviewed retrospectively. 12 cases were found, who were scrutinized for demographic characteristics, clinical presentation, radiologicalfindings, and past and present surgical details and outcomes like morbidity and mortality. MRI with MRCP was done in all cases of obstructive jaundice. Preoperative diagnosis on ultrasound and CECT abdomen was based on presence of cystic lesions and malignant features which include one or more findings of internal septations, mural nodules, papillary projections, and cyst wall enhancement were carefully looked for. Of the 12 cases, 8 cases, underwent enucleation and four cases underwent non anatomical resection. Follow up of patients for symptom recurrence was done by telephonic interview and outpatient visits. There has been no recurrence during the follow-up period ranging from six months to three years.

\section{OBSERVATION}

Of the 12 patients with biliary cystadenomas, there were eleven women and one man. The median age of the patients was 46 years (range 23-65 years). The most common symptom was abdominal pain (92\%), followed by abdominal distension, loss of appetite, and mass abdomen (Table 1). Of the 12 patients, three presented with features of obstructive jaundice. All patients were subjected to routine blood investigations with liver function tests and in addition Serum CA 19-9 was done which was normal in all patients. We had three patients who had protruding mass like lesion into the biliary tract causing obstruction to bile flow. Two patients underwent non anatomical liver resection along with extrication of the mass and one patient underwent excision of Extrahepatic biliary duct along with extrication of polypoidal mass with Hepaticojejunostomy. Enucleation/ Non anatomical resection was the preferred procedure and Hepaticojejunostomy was done when required. Postoperative complications were recorded and the pathology slides were reviewed. The three cases with obstructive jaundice are discussed in detail (Table 2 and Table 3).

\section{Case 1}

A 32-year-old female presented with complaints of abdominal pain and episodic jaundice over the past one year. She was icteric and her liver function tests showed a total bilirubin of $3.6 \mathrm{mg} / \mathrm{dL}(0.2$ to $1.2 \mathrm{mg} / \mathrm{dL})$; direct

Table 1: Patient's presenting complaints:

\begin{tabular}{lc} 
Clinical Features & $\mathbf{n ( \% )}$ \\
\hline Abdominal pain & $11(92)$ \\
Abdominal distension & $5(42)$ \\
Abdominal mass & $3(25)$ \\
Loss of appetite & $5(42)$ \\
Elevated bilirubin & $3(25)$ \\
\hline
\end{tabular}




\section{EDORiUM Journals}

Int J Hepatobiliary Pancreat Dis 2018;8:100078Z04SS2018.

www.ijhpd.com

Sugi R. V. et al. 3

Table 2: Patients demography and clinical presentation

\begin{tabular}{|c|c|c|c|c|c|}
\hline Case & Age/Sex & Presenting complaints & $\begin{array}{l}\text { Duration of } \\
\text { symptoms }\end{array}$ & Clinical finding & Abdominal findings \\
\hline 1 & $32 / F$ & $\begin{array}{l}\text { Abdominal pain with episodic } \\
\text { jaundice }\end{array}$ & 12 months & Icteric & Nil \\
\hline 2 & $60 / F$ & $\begin{array}{l}\text { Abdominal pain with episodic } \\
\text { jaundice }\end{array}$ & 6 months & Icteric & Nil \\
\hline 3 & $17 / \mathrm{F}$ & $\begin{array}{l}\text { Abdominal pain with episodic } \\
\text { jaundice }\end{array}$ & 4 months & Icteric & Nil \\
\hline
\end{tabular}

Table 3: Imaging findings, intra operative findings and procedure done

\begin{tabular}{|c|c|c|c|}
\hline Case & MRI findings & Procedure done & Findings \\
\hline 1. & $\begin{array}{l}\text { Well defined cystic lesion of size } 17.8 \times 11.4 \mathrm{cms} \\
\text { which is hypointense on T } 1 \text { and hyperintense on } \\
\text { T2 were seen in segments } 5,6 \text { and } 7 \text { of liver with } \\
\text { few thin internal septae, suspicious of a hydatid } \\
\text { cyst. No obvious intraluminal mass lesion in bile } \\
\text { duct. }\end{array}$ & $\begin{array}{l}\text { Non anatomical liver resection } \\
\text { of the lesion with extrication of } \\
\text { intraductal mass }\end{array}$ & $\begin{array}{l}\text { Bile duct was explored and a bile } \\
\text { stained membranous mass noted } \\
\text { within it. Choledochoscopy of the } \\
\text { proximal biliary tree up to the } \\
\text { second order division was found to } \\
\text { be normal. }\end{array}$ \\
\hline 2. & $\begin{array}{l}\text { Mixed signal intensity cystic lesion situated in } \\
\text { segment 4B of liver showing calcification and } \\
\text { septations extending upto porta hepatis with } \\
\text { dilated IHBR and EHBR. Cholangiogram showed } \\
\text { filling defect at hilum. }\end{array}$ & $\begin{array}{l}\text { Non anatomical liver resection } \\
\text { of the lesion with extrication of } \\
\text { intraductal mass and closure of } \\
\text { the communicating rent. }\end{array}$ & $\begin{array}{l}\text { Thick walled cystic lesion of size } \\
6 \times 5 \mathrm{~cm} \text { attached to inferior surface } \\
\text { of segment } 4 \mathrm{~B} \text { of liver. The cyst } \\
\text { had communication with hilar } \\
\text { confluence. }\end{array}$ \\
\hline 3. & $\begin{array}{l}\text { A well-definedseptated cystic lesion of size } \\
5.9 \times 2.4 \mathrm{~cm} \text { was seen in porta and communicating } \\
\text { anterosuperiorly with biliary confluence and } \\
\text { CHD. This lesion was causing mass effect on PV } \\
\text { and CBD. p/o Bile duct diverticulum. }\end{array}$ & $\begin{array}{l}\text { Excision of the extra hepatic } \\
\text { biliary apparatus along with } \\
\text { extrication of polypoidal lesion } \\
\text { from bile duct and closure of } \\
\text { communicating rent. }\end{array}$ & $\begin{array}{l}\text { Thick walled cystic lesion of } \\
\text { size } 5 \times 5 \mathrm{~cm} \text { attached to inferior } \\
\text { surface of caudate lobe. CHD and } \\
\text { proximal CBD were dilated by an } \\
\text { intraluminal mass with abrupt } \\
\text { tapering at supraduodenal portion. }\end{array}$ \\
\hline
\end{tabular}

component of 2.1mg/dL. Her Serum CA 19-9 was 28.9 $\mathrm{U} / \mathrm{mL}$ (0-37 U/mL). Her other blood investigations were normal. Echinococcal serology was equivocal. Magnetic resonance imaging (MRI) revealed a well-defined cystic lesion $(17.8 \mathrm{~cm} \times 11.4 \mathrm{~cm})$ in segments 5,6 , and 7 of the liver which was hypointense on $\mathrm{T} 1$ and hyperintense on T2 with few thin internal septae,suggestive of a hydatid cyst. No obvious intraluminal mass lesion in the bile duct could be discerned on MRI. She was optimized with a plan to resect the hydatid cyst. Intra operatively, following a non-anatomical liver resection of the lesion palpable mass was noted extending into the common hepatic duct from the distal divided end of the bile duct. The bile duct was explored and a bile-stained free floating membranous mass along with the bile duct was excised (Figure 1). The mass was excised along with the cuff of bile duct from where it was arising. A proximal check choledochoscopy was unremarkable. Biliary reconstruction was done by a Roux-en-Y hepaticojejunostomy (RYHJ). Her postoperative course was uneventful. Histopathology revealed the lesion to be a cyst lined by a single layer of low cuboidal epithelium, with the underlying stroma resembling ovarian stroma in places suggestive of a multilocular biliary cystadenoma. The patient is asymptomatic with a normal liver function test on follow-up.

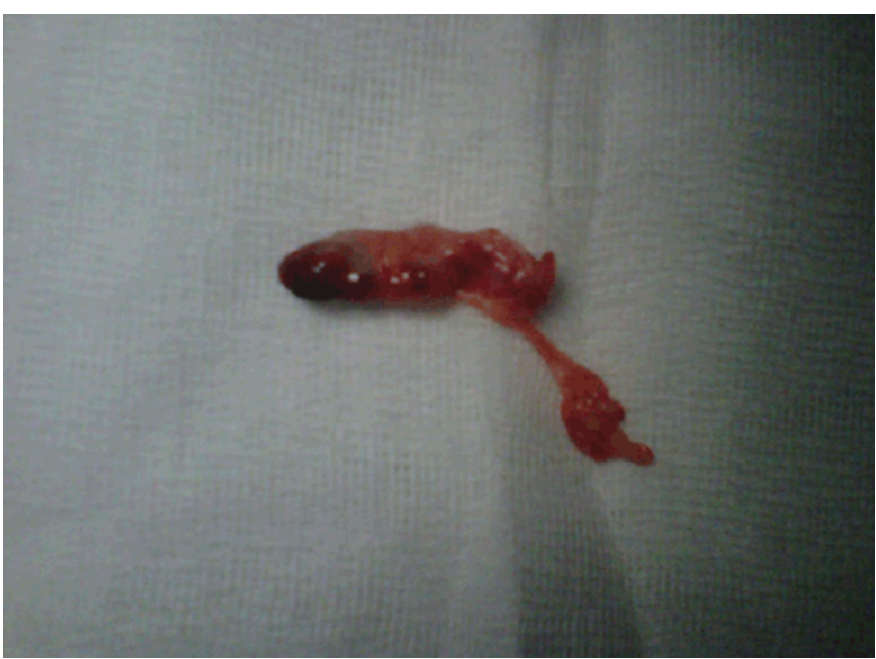

Figure 1: Intraluminal tumor cast extricated from bile duct. (Case 1).

\section{Case 2}

A 60-year-old female presented with complaints of abdominal pain with episodic jaundice of six months duration. Laboratory investigations showed cholestatic liver profile with normal white blood cell count and inflammatory marker levels. Her liver function tests 


\section{EDORiUM Journals}

showed a total bilirubin of $4.2 \mathrm{mg} / \mathrm{dL}(0.2$ to $1.2 \mathrm{mg} /$ $\mathrm{dL}$ ); direct component of $3.0 \mathrm{mg} / \mathrm{dL}$. Her liver enzymes were within normal limits.Her Serum CA 19-9 was 14.9 $\mathrm{U} / \mathrm{mL}$. Echinococcal serology was equivocal. Ultrasound (US) revealed a large $6 \times 5 \mathrm{~cm}$ cystic lesion in segment four of liver with multiple septations and appeared to be communicating with hepatic duct; floating debris with smooth narrowing distal to cystic duct common hepatic duct junction was also noted. MRI showed a cystic lesion segment $4 \mathrm{~b}$ of liver with calcification and septations extending upto porta hepatis with dilated intrahepatic and extra hepatic biliary tree. A diagnosis of biliary cystadenoma / hydatid cyst with possible rupture into bile duct was considered.She underwent an endoscopic retrograde cholangiopancreatography (ERCP) which showed a filling defect at hilum. She was offered surgery as a definitive treatment of her lesion in the liver, which was excised completely. A polypoid lesion was extricated from bile duct (Figure 2). A cystobiliary communication was noted which was sutured with $3-0$ vicryl along with T-Tube drainage of common bile duct (CBD). The T-tube was removed six weeks later following a normal check
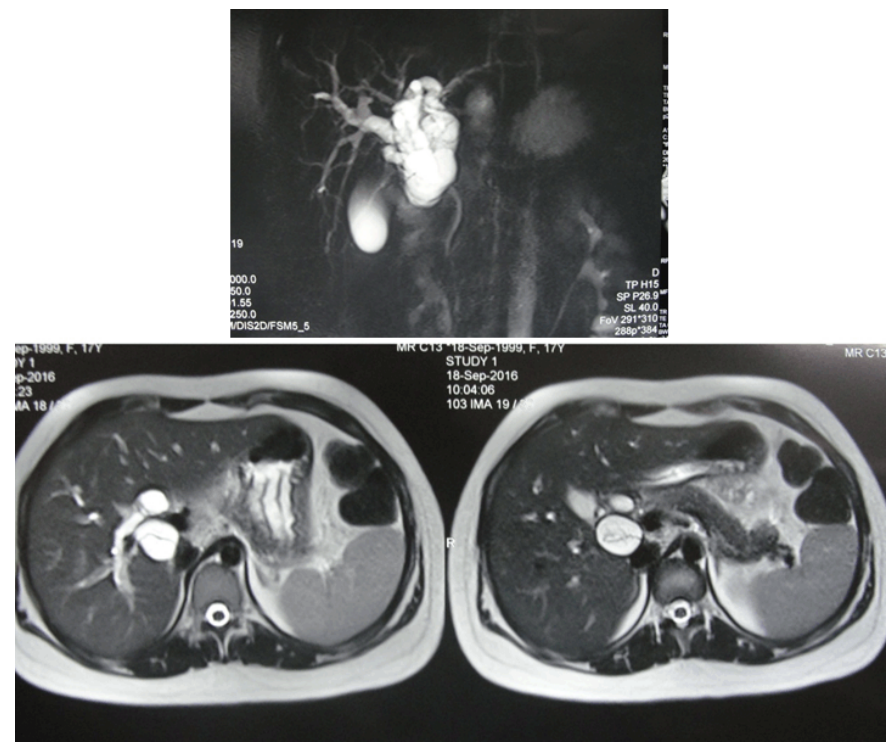

Figure 2(A and B): MRI showing a well-defined septatedcystic lesion of size $5.9 \times 2.4 \mathrm{~cm}$ arising from the caudate lobe, communicating with the biliary confluence and a stricture in the proximal CBD. (Case 2).

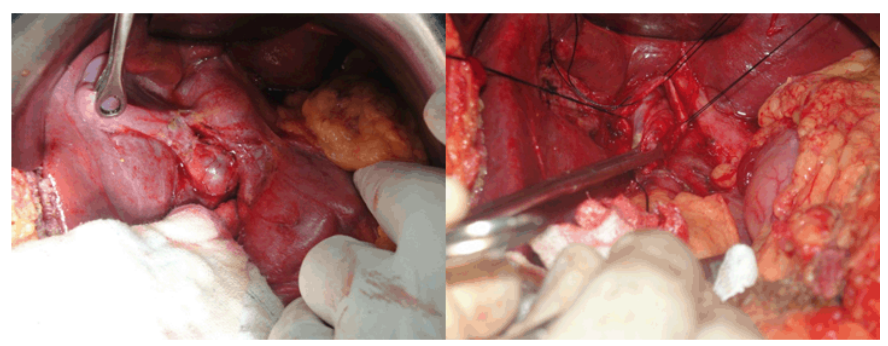

Figure 3(A and B): On table, she was noted to have a thick walled cystic lesion arising from the inferior surface of thecaudate lobe; this was excised completely. (Case 3). cholangiogram demonstrated no biliary leak.The patient is asymptomatic and anicteric on follow-up.

\section{Case 3}

A 17-year-old girl presented with complaints of frequent episodes of abdominal pain over the previous four months with intermittent episodes of jaundice and generalized pruritus. She was a recently diagnosed diabetic. Her laboratory investigations were unremarkable except for a serum total bilirubin ( $2.08 \mathrm{mg} / \mathrm{dl}$ ) (0.2 to 1.2 $\mathrm{mg} / \mathrm{dL}$ ) and serum alkaline phosphatase of $702 \mathrm{IU} / \mathrm{L}$ (44 to $147 \mathrm{IU} / \mathrm{L}$ ). Serum CA 19-9 was $66.47 \mathrm{U} / \mathrm{ml}$. MRI revealed a well-defined septated cystic lesion of size $5.9 \times 2.4 \mathrm{~cm}$ arising from the caudate lobe, communicating with the biliary confluence and a stricture in the proximal CB D (Figure $3 \mathrm{a}$ and $3 \mathrm{~b}$ ). The lesion was also compressing the portal vein (PV). At surgery, she was noted to have a thick walled cystic lesion arising from the inferior surface of the caudate lobe; this was excised completely. Cystobiliary communication along with a distended bile duct containing an intraluminal mass was noted. Excision of the extrahepatic biliary apparatus along with extrication of polypoidallesion from bile duct and the communicating rent was noted. Bile duct was excised just above the communication rent and biliary reconstruction was done using a Roux limb of jejunum.

\section{DISCUSSION}

BCA are most often seen in middle aged women and constitute less than $5 \%$ of cystic lesions of the liver. BCA was first reported by Hueter in 1887, while Keen reported the first resection of BCA 5 years later [8]. Traditionally, cystadenomas are thought to originate from the biliary epithelium, possibly from a congenitally aberrant bile duct. The tumors contain numerous internal septations and intraluminal papillary projections, which are lined by mucous-secreting cuboidal or columnar biliary epithelium. This epithelium is sometimes surrounded by a dense mesenchymal stroma containing smoothmuscle cells. A loose layer of collagen-containing blood vessels, nerves, and bile ducts further surrounds this area. True connections with the biliary tree are rare. Abdominal pain and an occasionally palpable mass are its usual presenting features; rare presentations such as vomiting, dyspepsia, anorexia, and weight loss have been described [1]. The cyst fluid is usually clear and mucinous, but may be bile stained, purulent, gelatinous or proteinaceous. Blood stained cyst fluid may be suggestive of a cystadenocarcinoma [2].

On routine imaging, cystadenomas are often difficult to differentiate from other liver cysts (simple liver cyst, hydatid cyst, haematomas, post-traumatic cysts, liver abscess, polycystic liver diseases), biliary cystadenocarcinoma, and metastatic lesions [3]. Extra hepatic biliary cystadenomas can typically 


\section{EDORIUM Journals}

mimic a choledochal cyst. Jaundice in a case of biliary cystadenoma may either be due to an extrinsic compression of the bile duct, accumulation of mucus secretion from a communicating biliary cystadenoma or by an intraluminal tumoural mass [4]. Cystadenomas have a hormone dependent growth as suggested by a notable increase in size during pregnancy and following oral contraceptives intake [5]. Recurrence of a liver cyst following partial resection or deroofing should raise a suspicion of biliary cystadenoma. They are usually large multiloculated cystic tumours and are pathologically of two types: with and without mesenchymal (ovarian-like) stroma [6]. The ovarian-like stroma, seen exclusively in females, consists of compact spindle shaped cell which support to the epithelium [9]. Microscopically, the loculi are lined by single layer of cuboidal or nonciliated columnar epithelium resting on a basement membrane with multiple polypoidal or papillary projections at some loci. The presence of mesenchymal ovarian like stroma offers a good prognosis as these are considered premalignant. Those without this stroma have a worse prognosis as they are most likely to be malignant [10]. Occasionally the dysplastic mucinous epithelium itself may proliferate within the bile ducts causing biliary obstruction [11].

This special entity referred as intraductal biliary cystadenomas is actually an intraductal papillary neoplasm with prominent cystic dilatation of the duct rather than a true biliary cystic neoplasm [12]. The narrow communication is usually not identified on routine imaging, but may easily be demonstrated on an intraoperative cholangiogram [13].

The diagnosis of BC may often be possible on routine ultrasonography, CT, and MRI abdomen. Ultrasound shows a well-demarcated and thick walled, globular or ovoid cyst with a non-calcified wall, with loculi, internal echoes, septations and at times papillary projections [10]. Upstream dilation of the biliary system may be demonstrable. Doppler study may depict flow within the cystic lesion [14]. CT demarcates the anatomic relation of the cystadenoma to the neighbouring structures, in addition to providing the details seen in ultrasound. Coarse calcifications in the internal septae when present can be visualized on CT [14]. MRI can be very useful in delineating the nature of fluid within the cyst; mucin favours a benign lesion whereas blood favours the diagnosis of a malignant lesion [2, 13]. Unfortunately, the preoperative radiological diagnostic accuracy for biliary cystadenomas may be as low as 30\% and may therefore be missed in the absence of a high index of clinical suspicion [15]. Features of malignancy includes an irregular thickness of the cyst wall, presence of mural nodules, hypervascularity of mural nodules and papillary projections [16]. Role of serum and cyst fluid CA 19-9 is still not completely understood. A normal level of CA 19-9 or CEA in serum/cyst fluid does not exclude a biliary cystadenoma. In such instances incomplete excision of the cyst is done resulting in recurrence. Another difficult task is to differentiate biliary cystadenomas from biliary cystadenocarcinomas, either before or during surgery.

Various treatment options for biliary cystadenomas include marsupialization, internal Roux-en-Y drainage, simple needle aspiration, injection sclerotherapy and partial resection. However, all these procedures have been fraught with high recurrence rates [17]. Complete resection is the treatment of choice as it minimizes the chances of recurrence [6]. In cases wherea resection may not be possible, simple enucleation is a safe and durable alternative [18]. We have managed three cases of intrahepatic biliary cystadenomas causing obstructive jaundice,with extrication of the polypoidalintraductal mass with or without non anatomical resection of adjoining liver parenchyma and restoring biliary continuity by doing hepatico jejunostomy in two cases. All three patients are on a regular follow up; they are asymptomatic with normal liver function tests and no recurrence.

\section{CONCLUSION}

In patients with obstructive jaundice, especially middle aged women, in the background of a cystic lesion in liver with or without a demonstrable biliary communication, intraductal biliary cystadenomas should be considered as a possible diagnosis and intra operative ultrasound should be done in all cases as it may be helpful in demonstrating the intraluminal mass in doubtful cases. It may often be possible to do a limited resection of the BCA with extrication of the benign intraluminal lesion. However, close follow up and periodic imaging is advisable to detect early recurrence.

\section{REFERENCES}

1. Florman SS, Slakey DP. Giant biliary cystadenoma: Case report and literature review. Am Surg 2001 Aug;67(8):727-32.

2. Manouras A, Markogiannakis $H$, Lagoudianakis E, Katergiannakis V. Biliary cystadenoma with mesenchymal stroma: Report of a case and review of the literature. World J Gastroenterol 2006 Oct 7;12(37):6062-9.

3. Palacios E, Shannon M, Solomon C, Guzman M. Biliary cystadenoma: Ultrasound, CT, and MRI. Gastrointest Radiol 1990 Fall;15(4):313-6.

4. Erdogan D, Busch OR, Rauws EA, van Delden OM, Gouma DJ, van-Gulik TM. Obstructive jaundice due to hepatobiliary cystadenoma or cystadenocarcinoma. World J Gastroenterol 2006 Sep 21;12(35):5735-8.

5. Emre A, Serin KR, Ozden I, et al. Intrahepatic biliary cystic neoplasms: Surgical results of 9 patients and literature review. World J Gastroenterol 2011 Jan 21;17(3):361-5. 


\section{EDORIUM Journals}

6. Vogt DP, Henderson JM, Chmielewski E. Cystadenoma and cystadenocarcinoma of the liver: A single center experience. J Am Coll Surg 2005 May;200(5):72733 .

7. Ahanatha Pillai S, Velayutham V, Perumal S, et al. Biliary cystadenomas: A case for complete resection. HPB Surg 2012;2012:501705.

8. Short WF, Nedwich A, Levy HA, Howard JM. Biliary cystadenoma. Report of a case and review of the literature. Arch Surg 1971 Jan;102(1):78-80.

9. Dixon E, Sutherland FR, Mitchell P, McKinnon G, Nayak V. Cystadenomas of the liver: A spectrum of disease. Can J Surg 2001 Oct;44(5):371-6.

10. Ferrozzi F, Bova D, Campodonico F. Cystic primary neoplasms of the liver of the adult. CT features. Clin Imaging 1993 Oct-Dec;17(4):292-6.

11. Del Poggio P, Buonocore M. Cystic tumors of the liver: A practical approach. World J Gastroenterol 2008 Jun 21;14(23):3616-20.

12. Zhou JP, Dong M, Zhang Y, Kong FM, Guo KJ, Tian YL. Giant mucinous biliary cystadenoma: A case report. Hepatobiliary Pancreat Dis Int 2007 Feb;6(1):101-3.

13. Yu FC, Chen JH, Yang $\mathrm{KC}$, Wu CC, Chou YY. Hepatobiliary cystadenoma: A report of two cases. J Gastrointestin Liver Dis 2008 Jun;17(2):203-6.

14. Zen Y, Fujii T, Itatsu K, et al. Biliary cystic tumors with bile duct communication: A cystic variant of intraductal papillary neoplasm of the bile duct. Mod Pathol 2006 Sep;19(9):1243-54.

15. Federle MP, Filly RA, Moss AA. Cystic hepatic neoplasms: Complementary roles of CT and sonography. Am J Roentgenol 1981 Feb;136(2):3458.

16. Choi BI, Lim JH, Han MC, et al. Biliary cystadenoma and cystadenocarcinoma: CT and sonographic findings. Radiology 1989 Apr;171(1):57-61.

17. Ishak KG, Willis GW, Cummins SD, Bullock AA. Biliary cystadenoma and cystadenocarcinoma: Report of 14 cases and review of the literature. Cancer 1977 Jan;39(1):322-38.

18. Teoh AY, Ng SS, Lee KF, Lai PB. Biliary cystadenoma and other complicated cystic lesions of the liver: Diagnostic and therapeutic challenges. World J Surg 2006 Aug;30(8):1560-6.

\section{$* * * * * * * * *$}

\section{Acknowledgements}

Dr. Sastha Ahantha Pillai, Dr. J. Saravanan \& Dr. Ashwin Rammohan

\section{Author Contributions}

Sugi R. V. Subramaniam - Substantial contributions to conception and design, Acquisition of data, Analysis and interpretation of data, Drafting the article, Revising it critically for important intellectual content, Final approval of the version to be published

Sugumar Chidambaranathan - Substantial contributions to conception and design, Acquisition of data, Analysis and interpretation of data, Drafting the article, Revising it critically for important intellectual content, Final approval of the version to be published

Senthil Kumar - Substantial contributions to conception and design, Acquisition of data, Analysis and interpretation of data, Drafting the article, Revising it critically for important intellectual content, Final approval of the version to be published

Prabhakaran Raju - Substantial contributions to conception and design, Acquisition of data, Analysis and interpretation of data, Drafting the article, Revising it critically for important intellectual content, Final approval of the version to be published

Jeswanth Sathyanesan - Substantial contributions to conception and design, Acquisition of data, Analysis and interpretation of data, Drafting the article, Revising it critically for important intellectual content, Final approval of the version to be published

Ravichandran Palaniappan - Substantial contributions to conception and design, Acquisition of data, Analysis and interpretation of data, Drafting the article, Revising it critically for important intellectual content, Final approval of the version to be published

\section{Guarantor of Submission}

The corresponding author is the guarantor of submission.

\section{Source of Support}

None.

\section{Consent Statement}

Written informed consent was obtained from the patient for publication of this case series.

\section{Conflict of Interest}

Authors declare no conflict of interest.

\section{Copyright}

(C) 2018 Sugi R. V. Subramaniam et al. This article is distributed under the terms of Creative Commons Attribution License which permits unrestricted use, distribution and reproduction in any medium provided the original author(s) and original publisher are properly credited. Please see the copyright policy on the journal website for more information. 


\section{EDORIUM Journals}

\section{ABOUT THE AUTHORS}

Article citation: Sugi R V, Sugumar C, Senthil Kumar P, Prabhakaran R, Jeswanth S, Ravichandran P. Extrahepatic intraductal biliary cystadenomas: Solving the mystery of "Idiopathic biliary obstruction"? A tertiary care institute experience. Int J Hepatobiliary Pancreat Dis 2018;8:100078Z04SS2018.

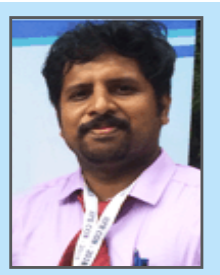

Sugi R. V. Subramaniam is Post Graduate Resident at Institute of Surgical Gastroenterology \& Liver Transplant ,Govt. Stanley Medical College, Chennai,Tamil Nadu, India. I earned from undergraduate degree (MBBS) from Madras Medical College, Chennai, India \& my Post Graduate degree (MS in General Surgery) from JIPMER, Puducherry, India. I am currently pursuing my Super Speciality (M.Ch in Surgical Gastroenterology) at Institute of Surgical Gastroenterology \& Liver Transplant,Govt. Stanley Medical College,Chennai, Tamil Nadu, India. My field of Interest is Heaptobiliaryand Liver/Pancreas Transplantation. I have published few case reports and original articles. Recently reviewed an article for Surgical Innovation. https://publons.com/author/1519279/sugi-r-v\#profile Email: drrvsugi@gmail.com

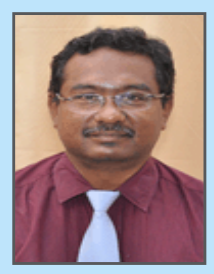

Sugumar Chidambaranathan is Professor Institute of Surgical Gastroenterology \& Liver Transplant Govt. Stanley Medical College Chennai, Tamil Nadu, India.

Email:dr.sugumar@yahoo.com

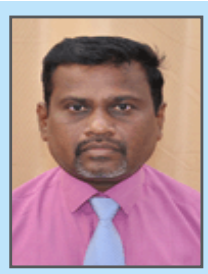

Senthil Kumar is Senior Assistant Professor, Institute of Surgical Gastroenterology \& Liver Transplant Govt. Stanley Medical College, Chennai, Tamil Nadu, India.

Email: dr.psenthil@yahoo.com

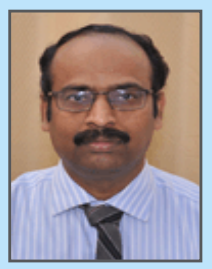

Prabhakaran Raju is Senior Assistant Professor, Institute of Surgical Gastroenterology \& Liver Transplant, Chennai, Tamil Nadu, India.

Email: kalprabha@gmail.com

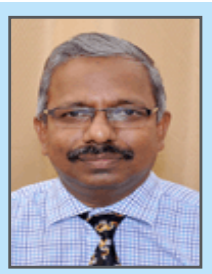

Jeswanth Sathyanesan is Professor, Institute of Surgical Gastroenterology \& Liver Transplant, Govt. Stanley Medical College, Chennai, Tamil Nadu, India.

Email: dr_jeswanth@yahoo.co.in

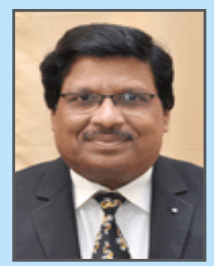

Ravichandran Palaniappan is Professor \& Head of Department, Institute of Surgical Gastroenterology \& Liver Transplant, Govt. Stanley Medical College, Chennai, Tamil Nadu, India.

Email: prahario5@yahoo.com 


\section{EDORIUM Journals}

Int J Hepatobiliary Pancreat Dis 2018;8:100078Z04SS2018.

www.ijhpd.com

Access full text article on other devices

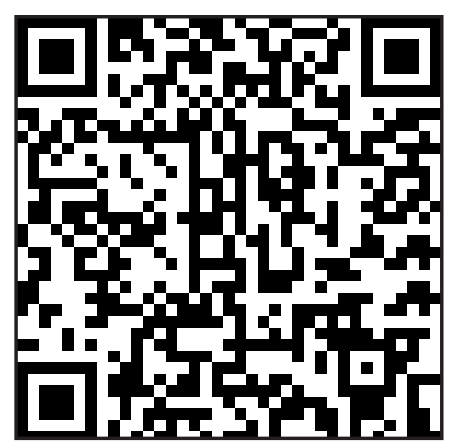

Access PDF of article on other devices

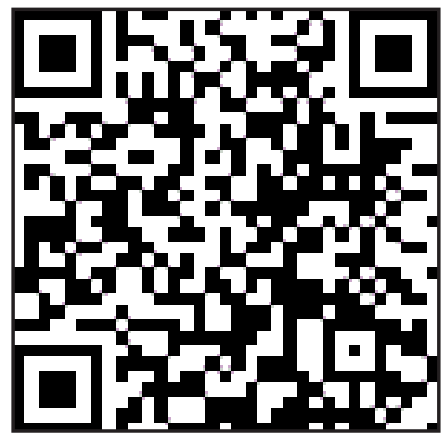

